\title{
DIAGNOSIS OF BLOOD LOSS BY THE METHOD OF DIGITAL STOKS POLARIMETRY OF HISTOLOGICAL SECTIONS OF RECTUS ABDOMINAL MUSCLE
}

\author{
Viktor Bachynskiy ${ }^{1}$, Oleh Vanchuliak ${ }^{2}$, Anastasiia-Vira Syvokorovska ${ }^{3}$, Marta \\ Garazdiuk $^{4}$, Alina Zavolovych ${ }^{5}$
}

Abstract: One of the important issues of forensic practice is the estimation of the volume of bleeding. Optical diagnostic methods of histological sections of tissue and liquids are perspective in this area.

Material and methods. The objects of investigation are native histological sections of rectus abdominal muscle, taken from 48 corpses with acute blood loss and 10 - control group with acute coronary death.

Results. The method of statistical analysis of the first-fourth Stokes vector parameters value distributions of microscopic images of histological sections of tissue with fibrillar structure (rectus abdominal muscle, skin, brain) of corpses with varying degrees of blood loss in order to estimate the bleeding volume was tested.

The most sensitive statistical moments of the third and fourth orders that characterize the asymmetry and the kurtosis of change the level of blood loss of the deceased $-\mathrm{V}=0 \mathrm{~mm} 3 \div 1000 \mathrm{~mm} 3$ were revealed.

UDC classification: 616.1, DOI: 10.12955/cbup.v7.1442

Keywords: blood loss, laser polarimetry, forensic medicine.

Introduction. Acute blood loss is one of the causes of death, which often occurs in the practice of forensic experts. Annually there is a tendency to increase such types of deaths. There are very few resources of information regarding the measurement of blood loss in the world literature.

Morphological changes of organs in acute blood loss are nonspecific, often varying and do not provide answers to a number of questions posed to the physician. Nowadays, microscopic tissue changes successfully are investigated on the micro level by methods of laser polarimetry (Ushenko et al., 2016; Ushenko et al., 2013). These methods have already demonstrated their effectiveness in the example of the research of tissues of the parenchymal organs, the skin, brain and liquids of the body for the diagnosis of post-mortem intervals (Ushenko et al., 2011; Garazdyuk et al., 2016; Ushenko et al., 2018).

Materials and methods. Our research was carried out according to a standard functional scheme of multiparameter polarization microscopy of biological preparations. Figure 1 demonstrates an optical circuit of a laser Stokes polarimeter (Ushenko et al., 2016; Ushenko et al., 2013): where: 1 - He-Ne laser; 2 - collimator; 3,5,8 - stationary quarter-wave plates; 4, 9 - polarizer and analyzer, respectively; 6 - biological preparations; 2, 7 - polarization micro lenses; 10 - CCD camera; 11 - personal computer.

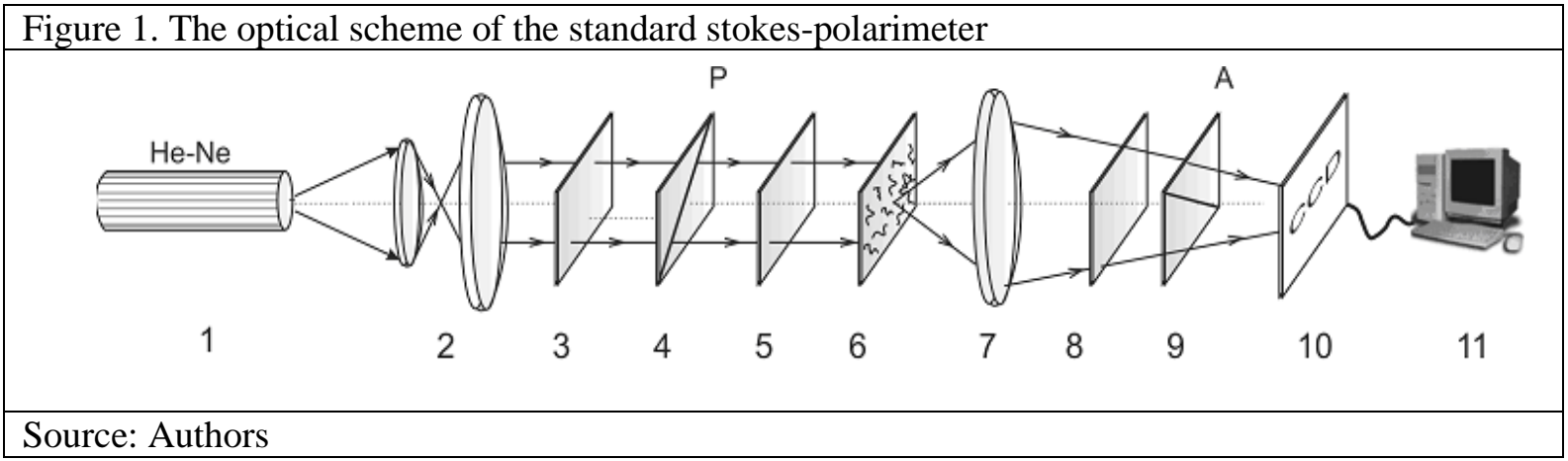

\footnotetext{
${ }^{1}$ Higher State Educational Establishment of Ukraine "Bukovinian State Medical University", Department of Forensic Medicine and Medical Law, Chernivtsi, Ukraine, sudmed@ bsmu.edu.ua

${ }^{2}$ Higher State Educational Establishment of Ukraine "Bukovinian State Medical University", Department of Forensic Medicine and Medical Law, Chernivtsi, Ukraine, wanchuliak@gmail.com

${ }^{3}$ Higher State Educational Establishment of Ukraine "Bukovinian State Medical University", Department of Forensic Medicine and Medical Law, Chernivtsi, Ukraine, nustusja@gmail.com

${ }^{4}$ Higher State Educational Establishment of Ukraine "Bukovinian State Medical University", Department of Forensic Medicine and Medical Law, Chernivtsi, Ukraine,m.garazdiuk@gmail.com

${ }^{5}$ Higher State Educational Establishment of Ukraine "Bukovinian State Medical University", Department of Forensic Medicine and Medical Law, Chernivtsi, Ukraine, sudmed@bsmu.edu.ua
} 
Objects of investigation. Samples were investigated (native histological sections with thickness of 30 micrometers) of tissues of organs with fibrillar structure: rectus abdominal muscle, skin, brain of corpses with varying degrees of blood loss:

$\begin{array}{ll}\text { - } & \mathrm{V}=0 \mathrm{~mm}^{3} \text { - group } 1 \text { (10 Samples); } \\ \text { - } & \mathrm{V}=500 \pm 100 \mathrm{~mm}^{3}-\text { gr. } 2 \text { (15 Samples); } \\ \text { - } & \mathrm{V}=1000 \pm 100 \mathrm{~mm}^{3}-\text { gr. } 3 \text { (14 Samples); } \\ \text { - } & \mathrm{V}=2000 \pm 100 \mathrm{~mm}^{3} \text { - gr. } 4 \text { (10Samples); } \\ & \mathrm{V}=2500 \pm 100 \mathrm{~mm}^{3} \text { - gr. } 5 \text { (5 Samples); }\end{array}$

The samples taken from 48 corpses with acute blood loss - the main research group and 10 samplescontrol group with acute coronary death. Pieces of organs with a thickness of $0.5 \times 0.5 \mathrm{~cm}^{2}$ were taken from corpses, cut using a freezing microtome without previous fixation and then sections were applied to an optically homogeneous glass.

Results. The main results of our investigation will be represented by one type of tissue - rectus abdominal muscle (RAM).

In Fig. 2 illustrated maps (fragments 1,3) and histograms (fragments 2, 4) of the phase parameter magnitude (hereinafter "phase parameter" - FP) distribution of microscopic images of the histological sections of RAM from group 1 (fragments 1,2) and group 3 (fragments 3, 4).

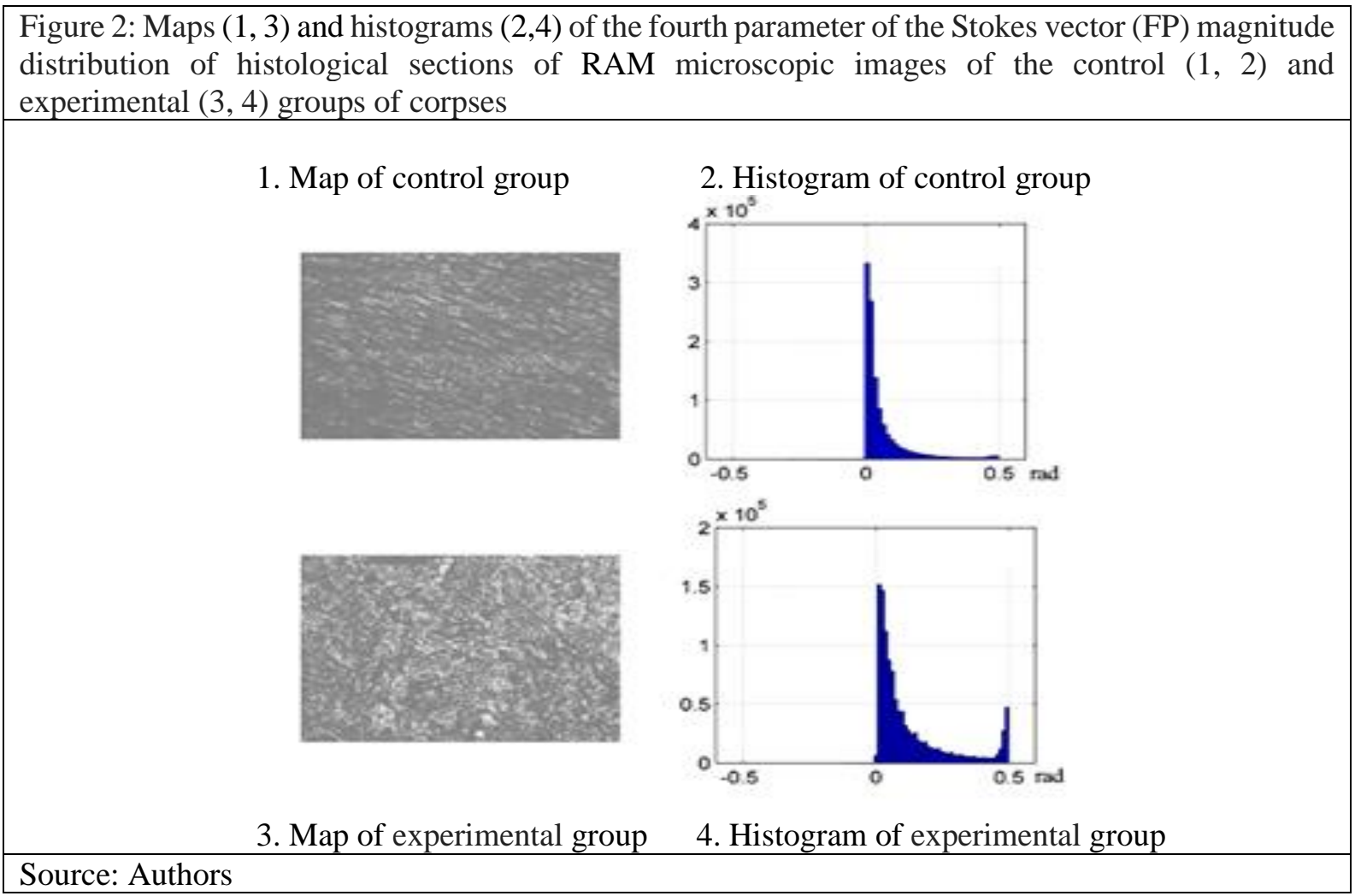

The results illustrate the presence of differences between the data of polarization microscopy of histological sections of RAM. Distributions of quantities the FP (Fig. 2, fragment 4) of the tissues of RAM with a higher level of blood loss $\left(\mathrm{V}=1000 \mathrm{~mm}^{3} \pm 100 \mathrm{~mm}^{3}\right)$ are characterized by a large average value and the range of spread of random values.

Proceeding from this fact we can assume the following scenario of the polarization manifestations of biological tissues of corpses blood loss:

1. With an increase in the degree of blood loss the concentration of blood elements decreases.

2. Optically this process is detected by an increase in the depth of phase modulation of laser radiation by optically anisotropic structures of biological tissue. 
3. Statistically the increase in blood loss is accompanied by an increase in the average and dispersion of the FP distributions (Fig. 2, fragments 2, 4).

4. Reduction of the concentration of shaped elements leads to a decrease in the magnitude of statistical moments of the 3rd and 4th orders, which characterize the distribution of FP of histological sections of biological tissues microscopic images.

Statistical moments of the 1st - 4th orders that shows this scenario of the change in the phase structure of microscopic images of RAM histological sections with different degrees of blood loss are given in Table 1:

\begin{tabular}{|c|c|c|c|}
\hline Blood loss, $\mathbf{m m}^{3}$ & $\mathbf{0}$ & $500 \mathrm{~mm}^{3} \pm 100 \mathrm{~mm}^{3}$ & $1000 \mathrm{~mm}^{3} \pm 100 \mathrm{~mm}^{3}$ \\
\hline Average, $\mathrm{SM}_{1}$ & $0.06 \pm 0.003$ & $0.105 \pm 0.004$ & $0.13 \pm 0.006$ \\
\hline Criteria, $t, p$ & $p<0.05$ & $p<0.05$ & $p<0.05$ \\
\hline Dispersion, $\mathrm{SM}_{2}$ & $0.09 \pm 0.004$ & $0.115 \pm 0.005$ & $0.14 \pm 0.006$ \\
\hline Criteria, $t, p$ & $\mathrm{p}<0.05$ & $\mathrm{p}<0.05$ & $\mathrm{p}<0.05$ \\
\hline Asymmetry, $\mathrm{SM}_{3}$ & $2.81 \pm 0.12$ & $2.15 \pm 0.105$ & $1.49 \pm 0.07$ \\
\hline Criteria, $t, p$ & $\mathrm{p}<0.05$ & $\mathrm{p}<0.05$ & $\mathrm{p}<0.05$ \\
\hline Kurtosis, $\mathrm{SM}_{4}$ & $8.51 \pm 0.38$ & $4.68 \pm 0.21$ & $1.05 \pm 0.05$ \\
\hline Criteria, $t, p$ & $p<0.05$ & $\mathrm{p}<0.05$ & $\mathrm{p}<0.05$ \\
\hline Blood loss, $\mathbf{m m}^{3}$ & $1500 \mathrm{~mm}^{3} \pm 100 \mathrm{~mm}^{3}$ & $2000 \mathrm{~mm}^{3} \pm 100 \mathrm{~mm}^{3}$ & $2500 \mathrm{~mm}^{3} \pm 100 \mathrm{~mm}^{3}$ \\
\hline Medium, $\mathrm{SM}_{1}$ & $0.155 \pm 0.007$ & $0.16 \pm 0.0075$ & $0.162 \pm 0.0076$ \\
\hline Criteria, $t, p$ & $p>0.05$ & $p>0.05$ & $p>0.05$ \\
\hline Dispersion, $\mathrm{SM}_{2}$ & $0.15 \pm 0.007$ & $0.152 \pm 0.007$ & $0.147 \pm 0.007$ \\
\hline Criteria, $t, p$ & $p>0.05$ & $p>0.05$ & $p>0.05$ \\
\hline Asymmetry, $\mathrm{SM}_{3}$ & $1.25 \pm 0.006$ & $1.19 \pm 0.006$ & $1.27 \pm 0.006$ \\
\hline Criteria, $t, p$ & $p>0.05$ & $p>0.05$ & $p>0.05$ \\
\hline Kurtosis, $\mathrm{SM}_{4}$ & $0.88 \pm 0.004$ & $0.69 \pm 0.003$ & $0.78 \pm 0.004$ \\
\hline Criteria, $t, p$ & $p>0.05$ & $p>0.05$ & $p>0.05$ \\
\hline
\end{tabular}

It was established:

- the range of changes in the magnitude of the statistical moments of the 1 st - 4th orders, which characterize the distribution of FP microscopic images of histological sections of RAM, is equal to the blood loss from $0 \mathrm{~mm}^{3} \div 1000 \mathrm{~mm}^{3}$;

- $S M_{1}$ varies within the range of the average value from 0.06 to 0.13 ;

- $S M_{2}$ varies within the range of the average value from 0,09 to 0,14 ;

- $S M_{3}$ varies within the range of the average value from 2,81 to 1,49 ;

- $S M_{4}$ varies within the range of the average value from 8,51 to 1,05 .

Fig. 3 shows Changes in the set of statistical moments $S M_{1 ; 2 ; 3 ; 4}$.

It is evident from the data obtained (Fig. 3) that the values of the average (SM1), dispersion (SM2), asymmetry (SM3) and kurtosis (SM4), which characterize the Stokes polarimetric maps of the histological sections of RAM, vary within the scope of blood loss from $0 \mathrm{~mm}^{3}$ to $1000 \mathrm{~mm}^{3}$. In this case, the most sensitive to such changes were - asymmetry and kurtosis.

The algorithm for determining the degree of blood loss are illustrated in Fig. 4.

\section{Conclusions}

A completely new methodical approach is proposed to solve the problem of estimation of the volume of blood loss on base of studying the native histological sections of rectus abdominal muscle. The dynamics of the change in the magnitude of the statistical moments of the 1st-4th order, which characterize the distributions of the phase parameter of polarization microscopic images of histological sections of the fibrillar tissues of the deceased (rectus abdominal muscle skin, kidney, brain) with different degrees of 
blood loss $-\mathrm{V}=0 \mathrm{~mm}^{3} \div 2500 \mathrm{~mm}^{3}$ were investigated. The sensitivity of Stokes polarimetry method to changes in tissues in case of blood loss in level from $0 \mathrm{~mm}^{3}$ to $1000 \mathrm{~mm}^{3}$ were revealed.

It is Figure 3. Dependences of average (SM1), dispersion (SM2), asymmetry (SM3) and kurtosis (SM4), which characterize Stokes polarimetric maps of histologic sections of RAM with varying degrees of blood loss.

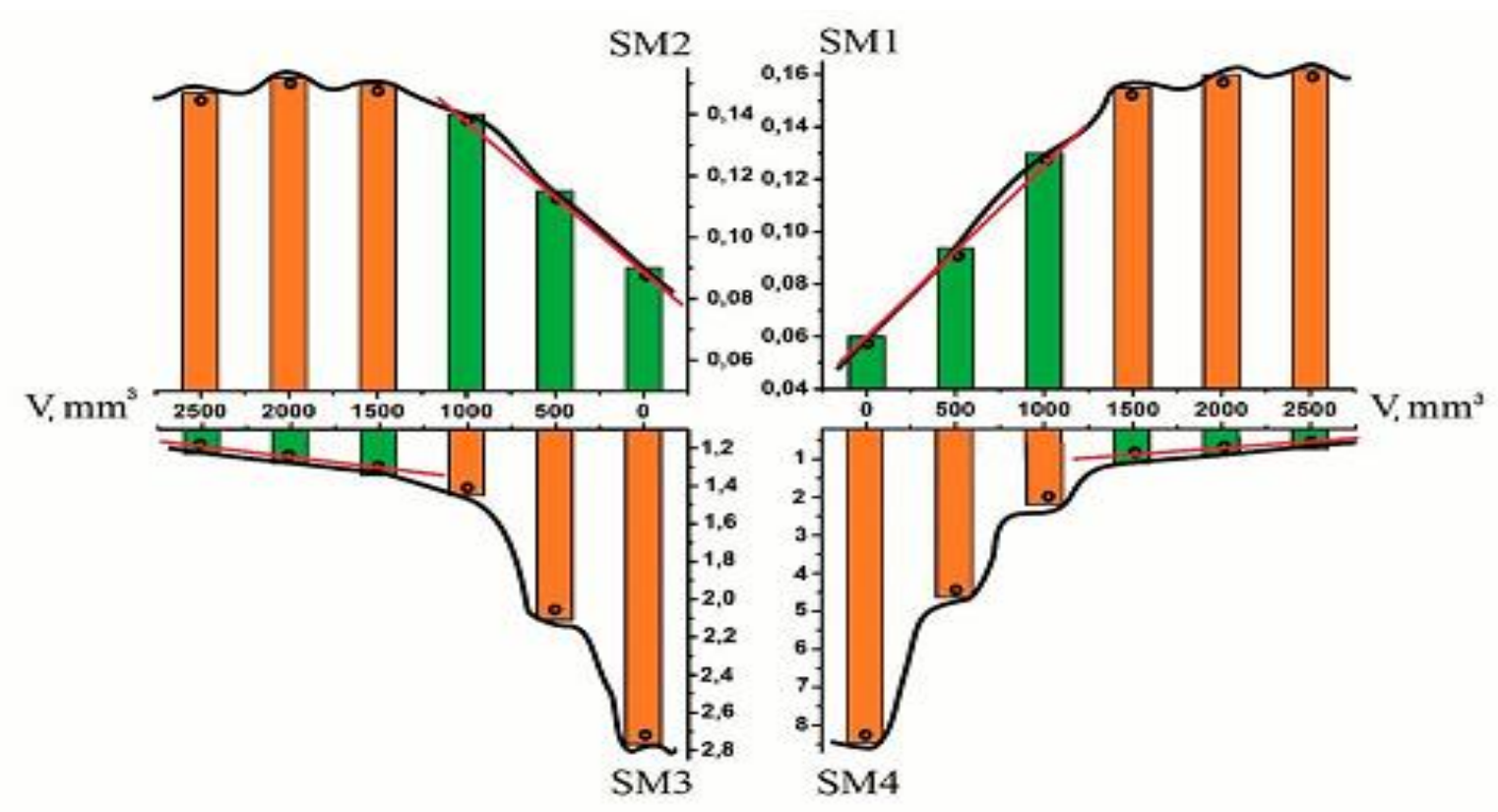

\section{Source: Authors}

It is Figure 4. Analytical scheme for determining the volume of blood loss of the dead method of polarization microscopy.

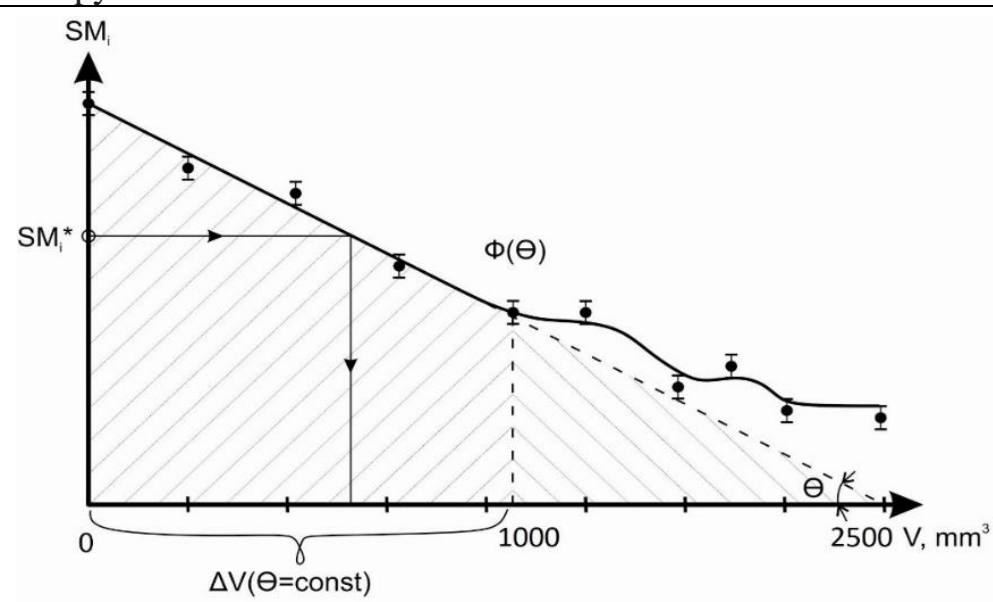

Source: Authors

Table 2: Accuracy of determining the volume of blood loss of histological sections of rectus abdominal muscle

\begin{tabular}{|l|c|c|c|c|c|}
\hline Blood loss, $\mathrm{mm}^{3}$ & $\begin{array}{l}500 \mathrm{~mm}^{3} \pm \\
100 \mathrm{~mm}^{3}\end{array}$ & $\begin{array}{l}1000 \mathrm{~mm}^{3} \pm \\
100 \mathrm{~mm}^{3}\end{array}$ & $\begin{array}{l}1500 \mathrm{~mm}^{3} \pm \\
100 \mathrm{~mm}^{3}\end{array}$ & $\begin{array}{l}2000 \mathrm{~mm}^{3} \pm \\
100 \mathrm{~mm}^{3}\end{array}$ & $\begin{array}{l}2500 \mathrm{~mm}^{3} \pm \\
100 \mathrm{~mm}^{3}\end{array}$ \\
\hline Average, $S M_{1}$ & 84 & 84 & 70 & 60 & 63 \\
\hline Dispersion, $S M_{2}$ & 78 & 74 & 67 & 60 & 61 \\
\hline Asymmetry, $S M_{3}$ & 86 & 84 & 72 & 63 & 64 \\
\hline Kurtosis, $S M_{4}$ & 88 & 86 & 74 & 61 & 66 \\
\hline
\end{tabular}




\section{References}

Ushenko, A. G., Dubolazov, A. V., Ushenko, V. A., Ushenko, Y. A., Sakhnovskiy, M. Y., Balazyuk, V. N., ... \& Meglinski, I. (2016, September). Polarization-correlation optical microscopy of anisotropic biological layers. In Applications of Digital Image Processing XXXIX (Vol. 9971, p. 99712C). International Society for Optics and Photonics. https://dx.doi.org/10.1117/12.2237926

Ushenko, Y. A., Dubolazov, A. V., Angelsky, A. P., Sidor, M. I., Bodnar, G. B., Koval, G., ... \& Junisbekov, M. S. (2013, January). Laser polarization fluorescence of the networks of optically anisotropic biological crystals. In Optical Fibers and Their Applications 2012 (Vol. 8698, p. 869809). International Society for Optics and Photonics. https://dx.doi.org/10.1117/12.2019350.

Ushenko, Y. A., Olar, O. I., Dubolazov, A. V., Balanetskaya, V. O., Unguryan, V. P., Zabolotna, N. I., \& Oleinichenko, B. P. (2011). Mueller-matrix diagnostics of optical properties inherent to polycrystalline networks of human blood plasma. Semiconductor Physics Quantum Electronics \& Optoelectronics. https://dx.doi.org/10.15407/spqeo14.01.098 Garazdyuk, M. S., Bachinskyi, V. T., Vanchulyak, O. Y., Ushenko, A. G., Dubolazov, O. V., \& Gorsky, M. P. (2016). Polarization-phase images of liquor polycrystalline films in determining time of death. Applied optics, 55(12), B67-B71. https://dx.doi.org/10.1364/AO.55.000B67

Ushenko, Y. O., Dubolazov, O. V., Ushenko, V. O., Zhytaryuk, V. G., Prydiy, O. G., Pavlyukovich, N., \& Pavlyukovich, O. (2018, January). Statistical analysis of polarization interference images of biological fluids polycrystalline films in the tasks of optical anisotropy weak changes differentiation. In Thirteenth International Conference on Correlation Optics (Vol. 10612, p. 106121Q). International Society for Optics and Photonics. https://dx.doi.org/10.1117/12.2305361 